\title{
Determining Infiltration Rates and Predicting Building Occupancy Using $\mathrm{CO}_{2}$ Concentration Curves
}

\author{
P. Parsons \\ Faculty of Engineering and Applied Science, Memorial University of Newfoundland, St. John's, NL, Canada A1C 5S7 \\ Correspondence should be addressed to P. Parsons; pp_314156@yahoo.com
}

Received 29 August 2013; Accepted 10 December 2013; Published 6 February 2014

Academic Editor: Harry Boyer

Copyright (C) 2014 P. Parsons. This is an open access article distributed under the Creative Commons Attribution License, which permits unrestricted use, distribution, and reproduction in any medium, provided the original work is properly cited.

\begin{abstract}
Demand controlled ventilation (DCV) reduces energy loss by reducing the air exchange flow rate to the minimum required to maintain acceptable indoor air quality (IAQ). DCV commonly uses carbon dioxide $\left(\mathrm{CO}_{2}\right)$ as a proxy for human activity and increases the ventilation rate once a preset $\mathrm{CO}_{2}$ threshold is exceeded. Significant improvements over threshold based ODV strategies are possible if the natural infiltration rate of the building is measured and the occupancy schedule determined by analysing the $\mathrm{CO}_{2}$ concentration continuously. These calculated parameters allow mathematical modeling of the ventilated space and the determination of future $\mathrm{CO}_{2}$ concentrations and allow prediction of future ventilation demands. The natural infiltration rate and the onset and duration of vacancy periods in a residential dwelling were determined by analysing $\mathrm{CO}_{2}$ concentration data. Concentration declines which fit an exponential decay curve with a correlation coefficient $>0.90$ identified all vacancy periods. The measured natural infiltration rate was found statistically correlated with average wind speed. A dynamic predicted occupancy map was constructed that has the potential to facilitate significant energy savings via deferred ventilation and intelligent cooling and heating strategies.
\end{abstract}

\section{Introduction}

The energy required for heating, ventilation, and air conditioning (HVAC) of buildings can be reduced by minimizing uncontrolled air infiltration through leaks in the building envelop. The natural air infiltration rate of older North American residential structures is large enough that IAQ is seldom a problem. However, the continuous air and vapour barrier installed in new construction has necessitated the introduction of mechanical ventilation systems to remove excess moisture and maintain acceptable IAQ. This mechanical ventilation is often provided by a heat or energy recovery ventilator (HRV, ERV) which is sized based on the number and types of rooms and provides a fixed quantity of air exchanges per hour $(\mathrm{ACH})$. This static approach results in excessive ventilation and energy waste during periods of low occupancy.

DCV systems reduce these losses by varying the ventilation rate as needed to maintain a minimum acceptable IAQ. These systems typically use $\mathrm{CO}_{2}$ as a proxy for IAQ and trigger additional ventilation once a threshold is exceeded. Unfortunately, using a gas sensor as a demand switch wastes the opportunity to derive additional information from the continuous analysis of $\mathrm{CO}_{2}$ concentration, including the natural infiltration of the space being ventilated and its patterns of occupancy. In order to enable intelligent DCV strategies that can reduce energy waste by supplying heating and cooling only when necessary and eliminate overventilation, the characteristics of the building and its usage patterns are required. The natural infiltration rate is required to determine the current $\mathrm{CO}_{2}$ generation rate and to predict future $\mathrm{CO}_{2}$ concentrations. Decisions to defer ventilation or plan a heating and cooling schedule require a knowledge of upcoming occupancy patterns. While the occupancy schedule could be entered manually by occupants similar to programming a thermostat, the infiltration rate would require a gas diffusion study. The ideal control system would learn by analysing realtime $\mathrm{CO}_{2}$ concentration data and require minimal user setup. Currently available control systems for residential use do none of this, using simple on and off controls and a humidistat. Unfortunately, humidity is a poor proxy for human generated pollutants because it varies slowly as weather patterns change and with the seasons except for short periodic spikes driven by bathroom showers. Furthermore, natural 
infiltration rates are seldom known and the standard blower door tests provide leakage data at $50 \mathrm{~Pa}$ which far exceeds normal conditions.

To confirm the assumption that an HVAC control system can learn building occupancy and calculate the natural infiltration rate from an analysis of $\mathrm{CO}_{2}$ concentration data, the author equipped a residential dwelling with a modified ventilation system and instrumentation for the continuous recording of $\mathrm{CO}_{2}$. The data was used to generate a weekly occupancy map and the natural infiltration rate was calculated every time the dwelling became vacant.

This paper presents the results of analysing the $\mathrm{CO}_{2}$ concentration curves, the generated vacancy map, and the correlation between natural infiltration and wind speeds and its implication for improved HVAC control systems.

\section{Background}

Occupant comfort is affected by temperature, humidity, odours, and $\mathrm{CO}_{2}$. The permissible exposure limit for $\mathrm{CO}_{2}$ is $5000 \mathrm{ppm}$ [1] which far exceeds levels that will be encountered in a home. Yawning is not caused by $\mathrm{CO}_{2}$ even at concentrations of $30,000 \mathrm{ppm}$ [2, p.384]; however, $20 \%$ of visitors are dissatisfied with body odours at $\mathrm{CO}_{2}$ concentrations of $1880 \mathrm{ppm}$ [3]. $\mathrm{CO}_{2}$ generation is a function of the quantity and size of the occupants and their activity levels. $\mathrm{CO}_{2}$ also correlates proportionally with pollutants such as body odour and in a more general manner with cooking, cleaning, or smoking that produce volatile organic compounds (VOC), moisture, and particles. This makes $\mathrm{CO}_{2}$ a useful proxy for $\mathrm{IAQ}$ and for controlling ventilation systems.

Since $\mathrm{CO}_{2}$ is nonreactive in the indoor environment and the dwelling volume is a constant, the total mass of $\mathrm{CO}_{2}$ and therefore its concentration can change only if more is added by human activity or if it is diluted via air exchange from outside. The portion of $\mathrm{CO}_{2}$ concentration change over time within the dwelling due to human activity is the $\mathrm{CO}_{2}$ generation rate divided by the total volume of the ventilated area. Assuming that the indoor air is well mixed and therefore the concentration throughout the building is a constant at any instant, the rate of concentration change due to outgoing exhaust air is the mechanical ventilation rate times the indoor concentration divided by the room volume. Similarly since the outdoor concentration is approximately a constant, the change due to incoming fresh air is the mechanical ventilation rate times the outdoor $\mathrm{CO}_{2}$ concentration divided by the room volume. This is expressed as a differential equation:

$$
\frac{d C(t)}{d t}=\frac{R}{V}\left(C_{a}-C(t)\right)+\frac{G}{V},
$$

where $C(t)$ is indoor concentration of $\mathrm{CO}_{2}$ at time $t$ (mass/ volume), $R$ is mechanical ventilation rate (volume/time), $V$ is dwelling volume, $C_{a}$ is ambient atmospheric $\mathrm{CO}_{2}$ concentration (mass/volume), and $\mathrm{G}$ is $\mathrm{CO}_{2}$ generation rate by occupants (mass/time).

Separating the variables and integrating $d t$ from zero to $t$ and $d C(t)$ from $C(0)$ to $C(t)$ we obtain:

$$
C(t)=C_{a}+\frac{G}{R}+\left(C(0)-C_{a}-\frac{G}{R}\right) e^{-(R / V) t}
$$

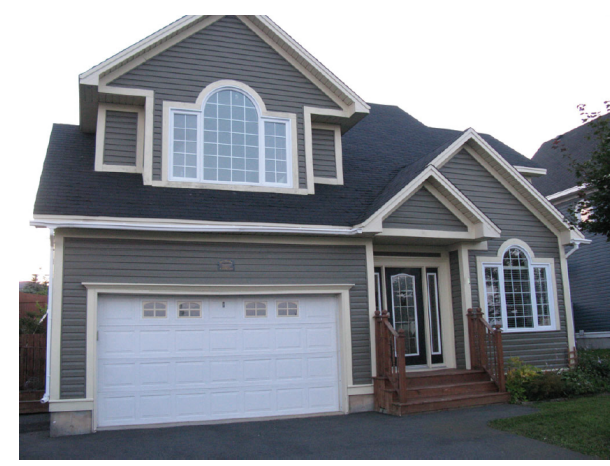

FIGURE 1: Canadian home built in 2003.

where $C(t)$ is indoor concentration of $\mathrm{CO}_{2}$ at time $t$ (mass/volume) and $\mathrm{C}(0)$ is initial indoor $\mathrm{CO}_{2}$ concentration (mass/volume).

When all occupants vacate a dwelling, the remaining $\mathrm{CO}_{2}$ can be used as a tracer gas to measure the natural infiltration rate. When the house is vacant, $G$ is zero and the $\mathrm{CO}_{2}$ concentration is a decaying exponential asymptotic to $C_{a}$. The beginning of the exponential decay marks the onset of vacancy and the natural infiltration rate of the dwelling is its volume divided by the time constant of the decaying exponential.

The $\mathrm{CO}_{2}$ generation rate of twenty adults between 21 and 28 years of age, standing and sitting at a desk, was found to average $0.24 \mathrm{~L} / \mathrm{min}$ and $0.18 \mathrm{~L} / \mathrm{min}$, respectively [4]. Assuming that household activities such as standing at a kitchen counter or watching television require similar effort, the $\mathrm{CO}_{2}$ generation rate for three adults, (3), would be $79.1 \mathrm{~g} / \mathrm{hr}$. Substituting this into (2) with large $t$ and a natural infiltration rate of $80 \mathrm{~m}^{3} / \mathrm{hr}$ yields (4). Therefore, the maximum $\mathrm{CO}_{2}$ concentration in a well-mixed home with leakage of $80 \mathrm{~m}^{3} / \mathrm{hr}$ and three low activity adults would be 1175 ppm:

$$
\begin{gathered}
G(t)=3 \times 0.24 \times 60 \times \frac{41.01}{22.4}=79.1 \mathrm{~g} / \mathrm{hr} \\
C(\infty)=400+\frac{79.1}{80 \times 1.2754} \times 1000=1175 \mathrm{ppm} .
\end{gathered}
$$

\section{Methodology}

Testing was performed on an occupied two-story, $650 \mathrm{~m}^{3}$, wood-framed home, Figure 1, built to Canadian residential standards in 2003. The air change rate with $50 \mathrm{~Pa}$ depressurization, $\eta_{50}$, was 2.55 air changes per hour $(\mathrm{ACH})$. The maximum flow rate of the HRV was $385 \mathrm{~m}^{3} / \mathrm{hr}$ with fresh air ducts into bedrooms and living areas and return ducts in bathrooms and kitchen. The kitchen and bathrooms were equipped with dedicated exhaust fans and operable windows.

The HRV unit was modified for computer control of recirculation and fan speed. A Figaro K30 nondispersive infrared (NDIR) $\mathrm{CO}_{2}$ sensor was installed in a central sampling device for differential measurements between the indoor and outdoor air streams. Figure 2 shows the HRV unit with the 


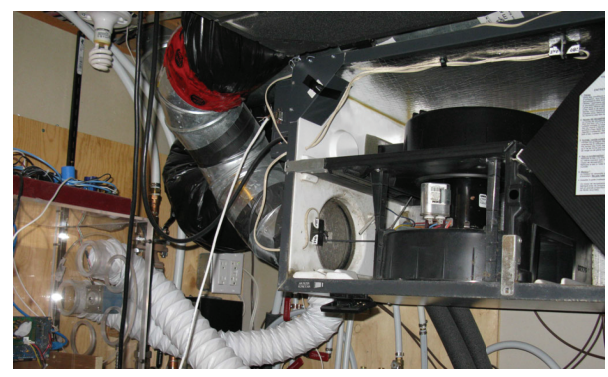

FIGURE 2: HRV and air sampler.

access door open. The translucent box to the left of the HRV is the air source selector which also contains the NDIR sensor.

The $\mathrm{CO}_{2}$ concentration was measured at the return duct every 180 seconds while the HRV recirculated air at $153 \mathrm{~m}^{3} / \mathrm{hr}$. Every 2.5 hours recirculation was disabled and fresh air was pumped into the building at $385 \mathrm{~m}^{3} / \mathrm{hr}$. Once the fresh air readings stabilized the $\mathrm{CO}_{2}$ concentration was recorded and the system reverted to recirculation at $153 \mathrm{~m}^{3} / \mathrm{hr}$. All measurements were logged into a database.

A moving window of $200 \mathrm{CO}_{2}$ concentration values, corresponding to 8.3 hours, was curve-fit to a theoretical decay by subtracting the background $\mathrm{CO}_{2}$ concentration from each datum and then taking its natural logarithm. The linearised data were then fit to a straight line using the least squares method. The window was advanced one data point at a time until the correlation coefficient $R^{2}$, calculated as per (5), peaked at a value $\geq 0.90$ marking the beginning of a vacancy period. The window was further advanced sequentially until $R^{2}$ dropped below 0.50 , marking the end of the vacancy period. Each exponential decay meeting the criteria $R^{2}>0.90$ was then mapped into one-hour time slots to produce an occupancy map. The map was then compared with personal notes from the occupants for verification:

$$
\begin{gathered}
\text { slope }=\frac{\sum x y-\sum x \sum y}{\sum x^{2}-\sum x \sum x}, \\
\text { intercept }=\frac{\sum y}{n}-s \frac{\sum x}{n}, \\
\text { correlation }=1-\frac{\sum(y-i-x s)^{2}}{\sum\left(y-\sum y / n\right)^{2}},
\end{gathered}
$$

where $x$ is seconds elapsed from start of window, $y$ is natural $\log$ of $\mathrm{CO}_{2}$ concentration, and $n$ is number of measurements in window period.

A Davis Vantage Pro 2 weather station positioned $4 \mathrm{~m}$ above ground level and $5 \mathrm{~m}$ from the home was used to record local meteorological data.

\section{Results}

Sequences of exponential $\mathrm{CO}_{2}$ decline were identified and the curves they were fit to, shown as red segments in Figure 3, were superimposed on a graph of actual indoor and outdoor $\mathrm{CO}_{2}$ concentrations. These overlays were generated using

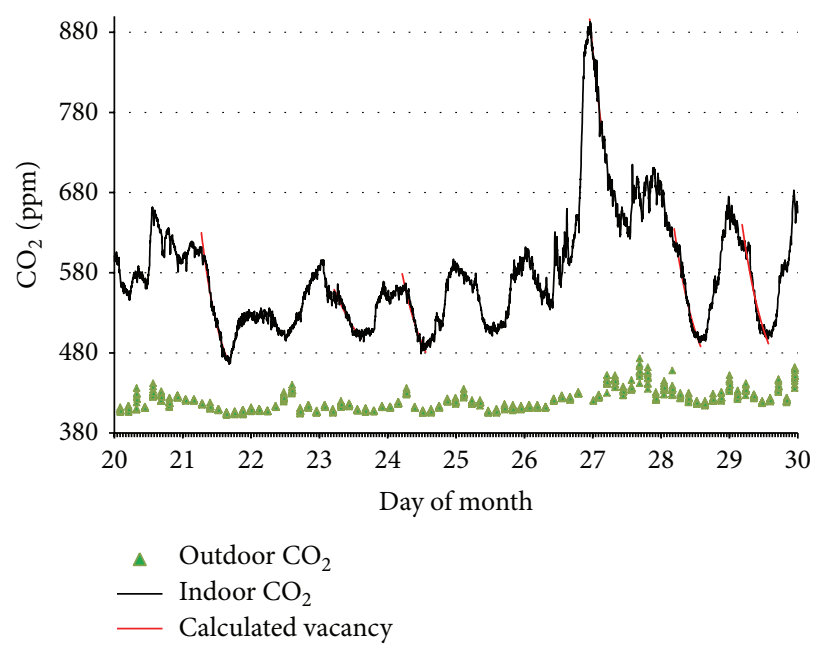

FIGURE 3: Estimated vacancy periods overlaid on actual data.

the equation calculated when the correlation coefficient was maximal and used to visually verify the fit.

Table 1 lists the start and end of potential vacancy periods, correlation with a pure exponential decay, decay time constant, lowest $\mathrm{CO}_{2}$, and whether the identification of vacancy was correct.

The vacancy map in Table 2 shows a weekly calendar with 24 hourly time slots. Each period shows the $\mathrm{CO}_{2}$ concentration at the end of the period. Cells with multiple values represent multiple vacancies during the same time slot, over the five-week observation period.

\section{Discussion}

Setting the threshold for correlation to $R^{2} \geq 0.90$ identified all true vacancies and included three false positives.

Using decays where $R^{2} \geq 0.95$, the $95 \%$ confidence interval for the mean of the decay constant during vacancies is (8.5, 11.5 ) hours with a standard deviation of 2.3 and mean of 10 hours.

Low wind speeds of $4 \mathrm{kmh}$ yielded an infiltration rate of $650 \mathrm{~m}^{3} / 12.2=53 \mathrm{~m}^{3} / \mathrm{hr}$. The mean time constant of 10 hours represents an infiltration rate of $650 \mathrm{~m}^{3} / 10=65 \mathrm{~m}^{3} / \mathrm{hr}$.

The infiltration rate was too low to return the indoor $\mathrm{CO}_{2}$ concentration to background levels for short vacancy periods so some vacancies would have been missed had the identification been based on absolute levels.

Table 3 shows a variation in infiltration rate with wind speed. The correlation between decay constants and average wind speed during the measurement period was significant with a Pearson correlation coefficient of -0.833 and a $P$ value of 0.001 . Figure 4 shows a negative correlation between the time constants and average wind speed which is expected. Wind direction is also a factor in asymmetrical houses as is turbulence [5-7]. The low end of the infiltration rate range can be used to conservatively predict $\mathrm{CO}_{2}$ and the end of a vacancy period, although if a wind sensor was installed the correlation could provide a better guess. 
TABLE 1: Vacancy periods identified via $\mathrm{CO}_{2}$ analysis.

\begin{tabular}{|c|c|c|c|c|c|}
\hline Fit $R^{2}$ & TC $(\mathrm{h})$ & Start (m-d hh:mm) & End (m-d hh:mm) & Low $\mathrm{CO}_{2}(\mathrm{ppm})$ & Wind $(\mathrm{kmh})$ \\
\hline 0.9811 & 6.0 & Jan-21 07:24 & Jan-21 16:43 & 466 & 15.2 \\
\hline 0.9178 & 15.3 & Jan-23 05:10 & Jan-23 14:41 & 495 & 9.7 \\
\hline 0.9460 & 7.6 & Jan-24 05:46 & Jan-24 13:16 & 479 & 9.0 \\
\hline 0.9817 & 12.2 & Jan-26 22:55 & Jan-27 06:33 & 676 & 4.1 \\
\hline 0.9614 & 7.8 & Jan-28 04:34 & Jan-28 13:52 & 493 & 9.7 \\
\hline 0.9330 & 7.9 & Jan-29 04:27 & Jan-29 13:40 & 497 & 8.7 \\
\hline 0.9593 & 9.9 & Jan-30 05:00 & Jan-30 14:23 & 531 & 3.0 \\
\hline 0.9291 & 6.3 & Jan-31 02:40 & Jan-31 12:26 & 489 & 18.7 \\
\hline 0.9586 & 7.0 & Feb-01 06:04 & Feb-01 15:29 & 502 & 15.6 \\
\hline 0.9800 & 7.4 & Feb-03 21:13 & Feb-04 06:26 & 483 & 16.1 \\
\hline 0.9804 & 7.1 & Feb-05 04:58 & Feb-05 13:59 & 470 & 15.9 \\
\hline 0.9560 & 17.9 & Feb-06 06:47 & Feb-06 16:25 & 517 & 4.7 \\
\hline 0.9473 & 13.6 & Feb-07 05:23 & Feb-07 14:27 & 527 & 3.1 \\
\hline 0.9451 & 9.0 & Feb-07 19:38 & Feb-08 04:48 & 475 & 19.1 \\
\hline 0.9617 & 3.4 & Feb-11 04:21 & Feb-11 13:54 & 432 & 8.5 \\
\hline 0.9625 & 9.8 & Feb-12 06:06 & Feb-12 15:14 & 488 & 5.7 \\
\hline 0.9341 & 8.6 & Feb-14 05:06 & Feb-14 13:43 & 470 & 12.4 \\
\hline 0.9373 & 11.6 & Feb-15 04:34 & Feb-15 14:44 & 474 & 9.2 \\
\hline 0.9460 & 06.7 & Feb-18 05:48 & Feb-18 15:10 & 452 & 11.6 \\
\hline 0.9482 & 15.8 & Feb-21 02:50 & Feb-21 12:15 & 522 & 10.4 \\
\hline 0.9631 & 13.2 & Feb-22 04:39 & Feb-22 14:29 & 498 & 4.5 \\
\hline 0.9714 & 12.5 & Feb-25 06:42 & Feb-25 15:53 & 498 & 3.5 \\
\hline 0.9532 & 09.6 & Feb-26 04:42 & Feb-26 13:49 & 471 & 5.5 \\
\hline 0.9486 & 16.6 & Mar-05 02:46 & Mar-05 12:35 & 475 & 18.6 \\
\hline 0.9795 & 12.7 & Mar-06 07:21 & Mar-06 16:24 & 456 & 5.9 \\
\hline 0.9791 & 11.4 & Mar-07 05:51 & Mar-07 15:02 & 468 & 4.0 \\
\hline 0.9336 & 31.5 & Mar-09 22:52 & Mar-10 09:25 & 568 & 10.1 \\
\hline
\end{tabular}

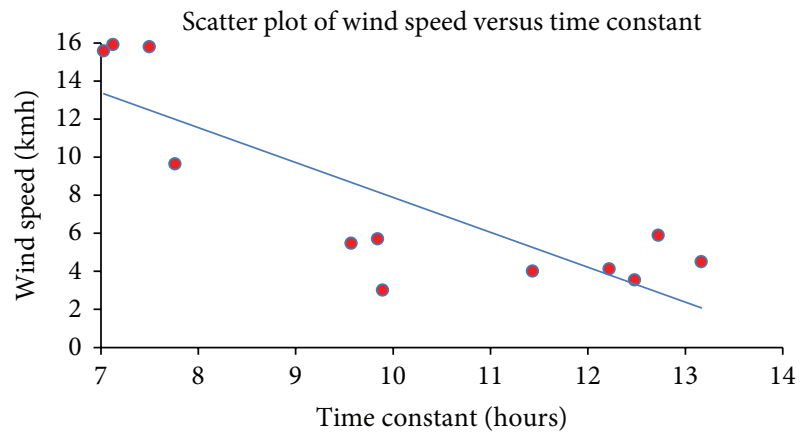

FIGURE 4: Correlation between wind speed and natural infiltration rate.

The maximum mechanical ventilation rate of the HRV was $384 \mathrm{~m}^{3} / \mathrm{hr}$; therefore, natural infiltration was approximately $17 \%$ of what the HRV was capable of providing. This natural leakage rate prevented interior $\mathrm{CO}_{2}$ levels from exceeding $710 \mathrm{ppm}$ during the observation period with one exception during a gathering of many people where it reached $880 \mathrm{ppm}$. Three adults engaged in light activity would have been expected to ultimately produce $\mathrm{CO}_{2}$ concentrations levels of approximately $650 \mathrm{ppm}$.
Periodic variation in outside $\mathrm{CO}_{2}$ concentrations, Figure 3 lower green line, was correlated with changes in indoor concentrations. The intake and exhaust vents from the HRV were installed as per building code but this resulted in mixing of the air streams that varied with atmospheric conditions. To improve the accuracy of outdoor readings, an extension duct was added to the exhaust vent which greatly reduced mixing. Random mixing made differential measurements inaccurate and resulted in missing most vacancy periods because of lower $R^{2}$ values. Since the NDIR sensor drift was negligible, the analysis was based solely on absolute indoor concentrations.

During the observation period, $\mathrm{CO}_{2}$ concentrations never exceeded $710 \mathrm{ppm}$ with three occupants indicating that the greatest saving from DCV would come from disabling fresh air intake most of the time.

A control system which has learned the occupancy map and average infiltration rate over a period of a few weeks could be implemented as follows.

If the $\mathrm{CO}_{2}$ rises above a threshold then look ahead to the next hourly time slot. If the probability of vacancy exceeds $50 \%$, calculate the $\mathrm{CO}_{2}$ concentration at the end of the projected vacancy using the average infiltration rate. If this is less than the threshold, then do not introduce fresh air. 
TABLE 2: Vacancy map for $R^{2} \geq 0.93$.

\begin{tabular}{lccccccc}
\hline Hour & Sun. & Mon. & Tue. & Wed. & Thu. & Fri. & Sat. \\
\hline 1 & 13 & 0 & 0 & 0 & 14 & 0 & 29 \\
2 & 13 & 0 & 0 & 0 & 14 & 0 & 29 \\
3 & 13 & 0 & 13 & 0 & 29 & 0 & 29 \\
4 & 13 & 0 & 13 & 0 & 29 & 0 & 29 \\
5 & 13 & 25 & $\mathbf{5 0}$ & 0 & 29 & 29 & 29 \\
6 & 13 & 38 & $\mathbf{5 0}$ & 13 & $\mathbf{7 1}$ & 29 & 29 \\
7 & 13 & $\mathbf{5 0}$ & $\mathbf{6 3}$ & 25 & $\mathbf{7 1}$ & 43 & 29 \\
8 & 0 & $\mathbf{6 3}$ & $\mathbf{6 3}$ & 38 & $\mathbf{7 1}$ & 43 & 14 \\
9 & 0 & $\mathbf{6 3}$ & $\mathbf{6 3}$ & 38 & $\mathbf{7 1}$ & 43 & 14 \\
10 & 0 & $\mathbf{6 3}$ & $\mathbf{6 3}$ & 38 & $\mathbf{7 1}$ & 43 & 14 \\
11 & 0 & $\mathbf{6 3}$ & $\mathbf{6 3}$ & 38 & $\mathbf{7 1}$ & 43 & 0 \\
12 & 0 & $\mathbf{6 3}$ & $\mathbf{6 3}$ & 38 & $\mathbf{7 1}$ & 43 & 0 \\
13 & 0 & $\mathbf{6 3}$ & $\mathbf{6 3}$ & 38 & $\mathbf{7 1}$ & 43 & 0 \\
14 & 0 & $\mathbf{6 3}$ & $\mathbf{5 0}$ & 38 & $\mathbf{5 7}$ & 43 & 0 \\
15 & 0 & 38 & 13 & 38 & 29 & 43 & 0 \\
16 & 0 & 38 & 13 & 25 & 14 & 14 & 0 \\
17 & 0 & 13 & 0 & 25 & 0 & 0 & 0 \\
18 & 0 & 0 & 0 & 0 & 0 & 0 & 0 \\
19 & 0 & 0 & 0 & 0 & 0 & 0 & 0 \\
20 & 0 & 0 & 0 & 0 & 14 & 0 & 0 \\
21 & 0 & 0 & 0 & 0 & 14 & 0 & 0 \\
22 & 13 & 0 & 0 & 0 & 14 & 0 & 0 \\
23 & 13 & 0 & 0 & 0 & 14 & 0 & 29 \\
24 & 13 & 0 & 0 & 0 & 14 & 0 & 29 \\
\hline
\end{tabular}

The bold values indicated the periods of vacancy.

TABLE 3: Wind speed versus time constant.

\begin{tabular}{lccc}
\hline Wind $(\mathrm{kmh})$ & TC $(\mathrm{h})$ & $R^{2}$ & Infiltration $\left(\mathrm{m}^{3} / \mathrm{h}\right)$ \\
\hline 4.1 & 12.2 & 0.982 & 53 \\
9.7 & 7.8 & 0.961 & 84 \\
3.0 & 9.9 & 0.959 & 66 \\
15.6 & 7.0 & 0.957 & 92 \\
15.8 & 7.5 & 0.979 & 87 \\
15.9 & 7.1 & 0.979 & 91 \\
5.7 & 9.8 & 0.963 & 66 \\
4.5 & 13.2 & 0.963 & 49 \\
3.5 & 12.5 & 0.971 & 52 \\
5.3 & 9.6 & 0.953 & 68 \\
5.9 & 12.7 & 0.979 & 51 \\
4.0 & 11.4 & 0.979 & 57 \\
\hline
\end{tabular}

Scenario 1. The $\mathrm{CO}_{2}$ concentration is $800 \mathrm{ppm}$ above outdoor levels at 7:30 a.m. Monday morning, and the threshold for ventilation is $600 \mathrm{ppm}$ above background levels. Should mechanical ventilation be used to bring this down by 200 ppm?

The Monday 8 a.m. to 1 p.m. time slot was vacant the last five weeks without exception; the probability of vacancy is estimated at $100 \%$. Anticipating 5 hours of vacancy and time constant of 2.6 hours, $\mathrm{CO}_{2}$ should decayed to $800 * e-$ $(5 / 2.6)=117$ ppm above outdoor levels. This is negligible and well below the $600 \mathrm{ppm}$ threshold. Therefore, fresh air ventilation at 7:30 is not necessary and will not be required until some time after 1 p.m.

Scenario 2. Assume there will be a 1 hour vacancy, and that the probability is $75 \%$ that it will occur between 8 a.m to 9 a.m, otherwise conditions are identical to Scenario 1.

Since there is a greater than 50\% chance of upcoming vacancy the system expects $\mathrm{CO}_{2}$ should decay to $800 * e-$ $(1 / 2.6)=544 \mathrm{ppm}$ above outdoor levels. This is just below the threshold, so ventilation can be deferred.

Had this been a newer home with a tighter building envelop and a time constant of 12 hours, the system would expect $\mathrm{CO}_{2}$ to decay to $800 * e-(1 / 12)=736 \mathrm{ppm}$ above outdoor levels. In this case, fresh air would be provided until $\mathrm{CO}_{2}$ levels returned to a concentration that could be reduced to $600 \mathrm{ppm}$ by natural infiltration during the remainder of the vacancy period. Alternatively, the fan could be run at a lower speed sufficient to augment natural infiltration such that $600 \mathrm{ppm}$ was reached just as occupants were expected to return.

The major energy savings for such a control strategy would come from the following:

(1) automatically setting occupied and unoccupied temperatures based on the vacancy probability map;

(2) disabling fresh air ventilation when not needed, which in this case, for a threshold of $1000 \mathrm{ppm}$, would have been all the time;

(3) disabling fresh air ventilation before vacancy periods, which for a 9-5 work schedule might eliminate an hour of fresh air each work day depending on the initial concentrations.

\section{Conclusion}

Periods of vacancy in residential homes were successfully detected using occupant generated $\mathrm{CO}_{2}$ as a tracer gas and following the decay in concentration. An accurate occupancy map was generated, indicating the probability and duration of future vacancies. The upper and lower limits of natural infiltration were determined from the time constant of the decay and statistically correlated with wind speed as expected.

The control system for a residential DCV system could be enhanced to use these parameters to optimize energy losses by minimizing excess ventilation while maintaining IAQ. The vacancy map could also be used to automatically program heating and cool systems.

\section{Conflict of Interests}

The author declares that there is no conflict of interests regarding the publication of this paper.

\section{Acknowledgments}

The author thanks Dr. Tariq Iqbal for research guidance and the Faculty of Engineering and Applied Science, Memorial 
University of Newfoundland, Technical Services for manufacturing the sampler hardware.

\section{References}

[1] "Occupational safety and health standards, toxic and hazardous substances, table z-1 limits for air contaminants 29 cfr 1910. $1000, " 1970$.

[2] R. R. Provine, B. C. Tate, and L. L. Geldmacher, "Yawning: no effect of $3-5 \% \mathrm{CO}_{2}, 100 \% \mathrm{O}_{2}$, and exercise," Behavioral and Neural Biology, vol. 48, no. 3, pp. 382-393, 1987.

[3] "European collaborative action indoor air quality and its impact on man (eca) guidelines for ventilation requirements in buildings," Office for Publications of the European Communities, no. 11, 1992.

[4] C. Reiff, K. Marlatt, and D. R. Dengel, "Difference in caloric expenditure in sitting versus standing desks," Journal of Physical Activity and Health, vol. 9, no. 7, pp. 1009-1011, 2012.

[5] F. Pan, "Wind-induced internal pressures of buildings with multiple openings," Journal of Engineering Mechanics, vol. 139, no. 3, pp. 376-385, 2013.

[6] J. H. Oh, G. A. Kopp, and D. R. Inculet, "The UWO contribution to the NIST aerodynamic database for wind loads on low buildings: part 3. Internal pressures," Journal of Wind Engineering and Industrial Aerodynamics, vol. 95, no. 8, pp. 755-779, 2007.

[7] G. A. Kopp, J. H. Oh, and D. R. Inculet, "Wind-induced internal pressures in houses," Journal of Structural Engineering, vol. 134, no. 7, pp. 1129-1138, 2008. 


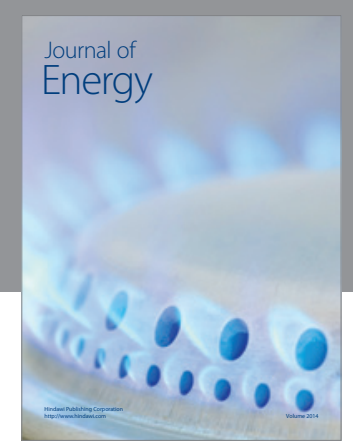

Journal of

Industrial Engineering
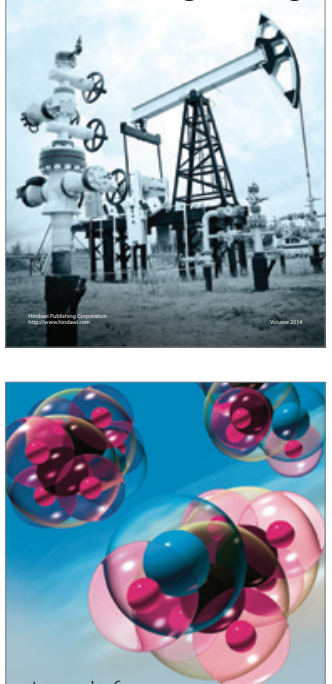

Fuels
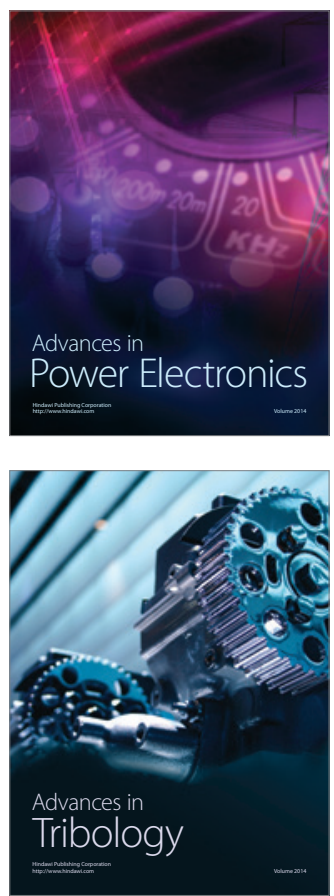

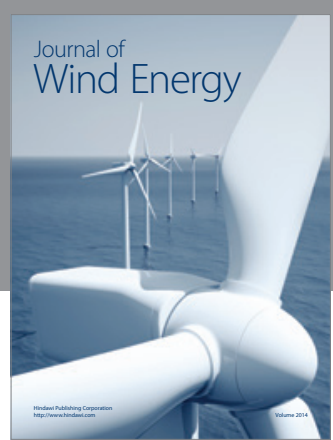

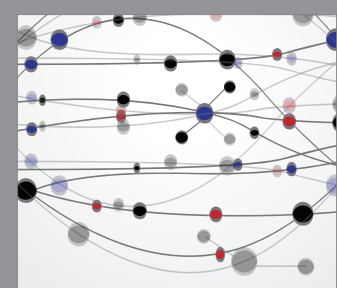

The Scientific World Journal

Submit your manuscripts at http://www.hindawi.com

Journal of

Structures
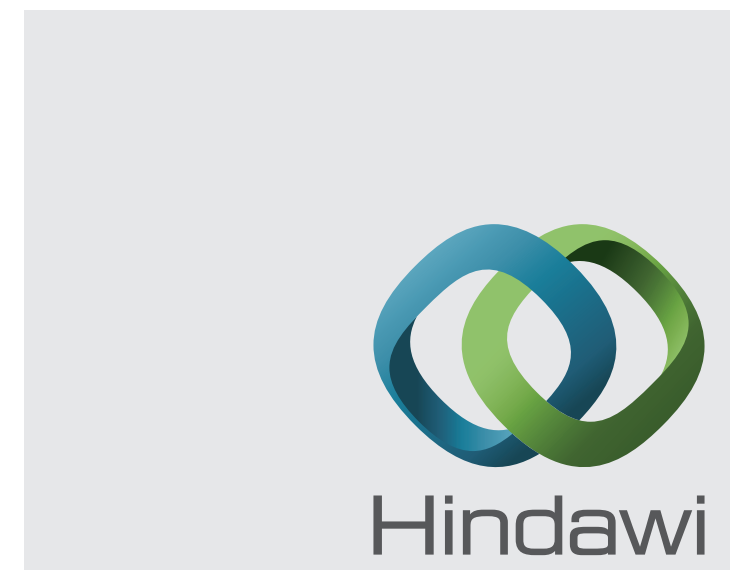

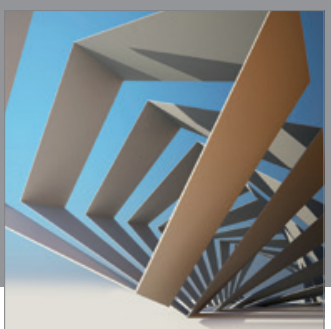

Rotating

Machinery
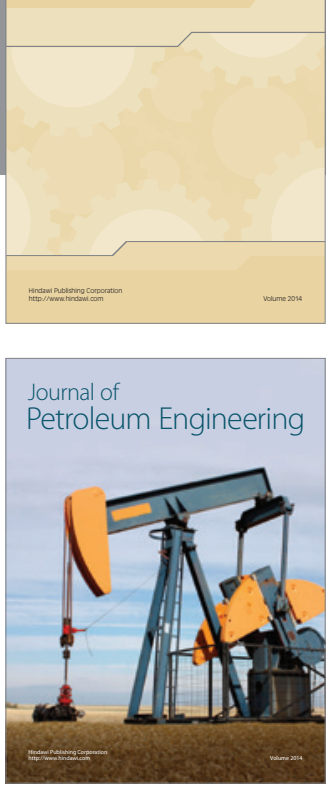

Journal of

Solar Energy
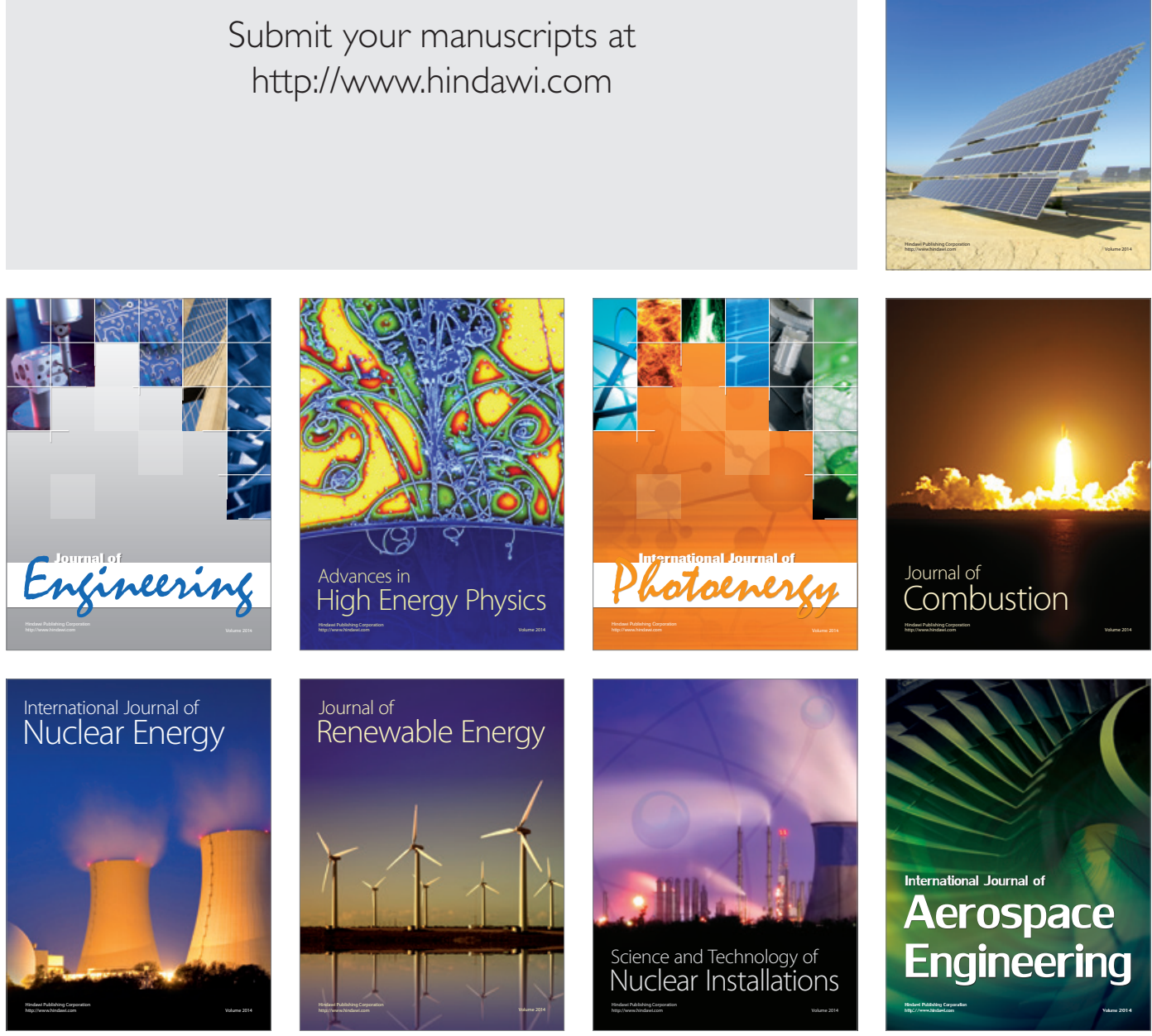